\title{
Effects of reducing sheep grazing in the Scottish Highlands
}

\author{
DIANE HOPE, NICHOLAS PICOZZI, DAVID C. CATT, AND ROBERT MOSS
}

\begin{abstract}
Authors are graduate student, Department of Plant and Soil Science, University of Aberdeen, Cruickshank Building, St. Machar Drive, Aberdeen AB9 2UD, Scotland; senior scientific officer, Institute of Terrestrial Ecology; higher scientific officer, Institute of Terrestrial Ecology; and principal scientific officer, Institute of Terrestrial Ecology, Hill of Brathens, Banchary, Kincardineshire AB3I $4 B Y$, Scotland.
\end{abstract}

\begin{abstract}
The effects of reducing sheep grazing on upland vegetation and wild herbivores was studied at 11 sites in the Scottish Highlands. Areas where sheep had been removed for periods of up to 25 years were compared with areas where stocking rates had remained unchanged. At 5 sites, removal of sheep was associated with taller vegetation and more signs of vole activity. While the removal of sheep appeared to have resulted in relatively few changes in floristic composition at these sites, patches of dwarf shrub-dominated vegetation tended to be larger and patches of grassland to be smaller where sheep had been removed. One previously open site was being invaded by birch woodland after sheep removal. At the remaining 6 sites removal of sheep appeared to have had little or no effect on vegetation or on wild herbivore activity. This was probably due to an increase in grazing by red deer, along with continued heather burning, at these sites. It is concluded that sheep removal is only likely to cause significant changes in vegetation composition and structure in the Scottish Highlands where red deer numbers are low and heather burning infrequent. When this occurs, vole numbers are likely to increase.
\end{abstract}

Key Words: sheep, red deer, sward structure, heather burning, voles.

The management of sheep plays an important role in the rangelands of upland Britain (Sydes and Miller 1988). This is because much upland vegetation in Britain is in a state of dynamic balance between graminaceous vegetation, dwarf shrubs, scrub and woodland, and grazing is crucial in helping to maintain this balance (Miles 1988). While the impacts of sheep grazing on the main successional pathways for upland vegetation are broadly known (Tansley 1939, Ratcliffe 1959, Miles et al. 1978), the effects of reducing sheep grazing on upland vegetation in Britain have largely been investigated using small fenced enclosures,

\footnotetext{
Authors thank the Scottish Office Agriculture and Fisheries Department for initiating the project, staff of the Macaulay Land Use Research Institute for help selecting field sites and providing computing facilities, Don French for help with data analysis, Eleanor Munro and David Scott for field assistance and Sheila Grant and John Miles for comments on early drafts of the manuscript. Thanks also to Scottish Natural Heritage and all the private estates who cooperated with the study. Manuscript accepted 15 Sep 95.
}

from which wild herbivores have usually been excluded (Jones 1967, Rawes 1981, Grant et al. 1985, Marrs et al. 1988). It may be misleading to use these findings to predict the effects of sheep removal on unfenced rangeland. Few grazing studies have been carried out on large exclosures or on open hillsides in upland Britain (Ball 1974, Welch 1984a) and none have assessed the effects of sheep grazing on wild herbivores. The aim of this study was to assess what effects there might be on common semi-natural upland vegetation communities and on the main wild vertebrate herbivores associated with them, when sheep were removed from large tracts of rangeland in the Scottish Highlands.

\section{Methods}

Since large-scale experimental manipulation of grazing is difficult and some changes take many years to develop (Miles et al. 1978, Marrs et al. 1988), a comparative survey approach was used at 11 study sites in the Scottish Highlands. At each site, floristic composition, vegetation structure and signs of herbivore activity on unimproved rangeland where sheep stocks had been maintained continuously (referred to as control areas) were compared with nearby areas which had formerly been stocked at similar rates, but where sheep had been removed for between 1 and 25 years (reduced-sheep areas).

\section{Site Selection}

Sites (Table 1) were selected to include the most common upland plant communities, to encompass a variety of management regimes (i.e., grazing intensity, frequency of heather burning) and to be large enough for assessing the effects of any grazing-induced vegetation changes on the main wild vertebrate herbivores (red deer Cervus elaphus, roe deer Capreolus capreolus, voles Microtus spp., mountain hares Lepus timidus, rabbits Oryctolagus cuniculus and red grouse Lagapus lagopus scoticus). As there are pronounced latitudinal variations in the composition of rangeland vegetation across the Scottish Highlands, related to the marked climatic gradient (Birse 1971, Nolan and Robertson 1987), sites were distributed within 3 broad bioclimatic regionswest (mild and wet), north (cool and wet) and east (cool and dry). Eleven paired sites were selected on soil and vegetation types typical of the bioclimatic regions (Fig. 1). Each site was roughly rectangular in plan, covered an area of between 30 and 100 ha and was divided evenly between control and reduced-sheep areas. 
Table 1. Site descriptions.

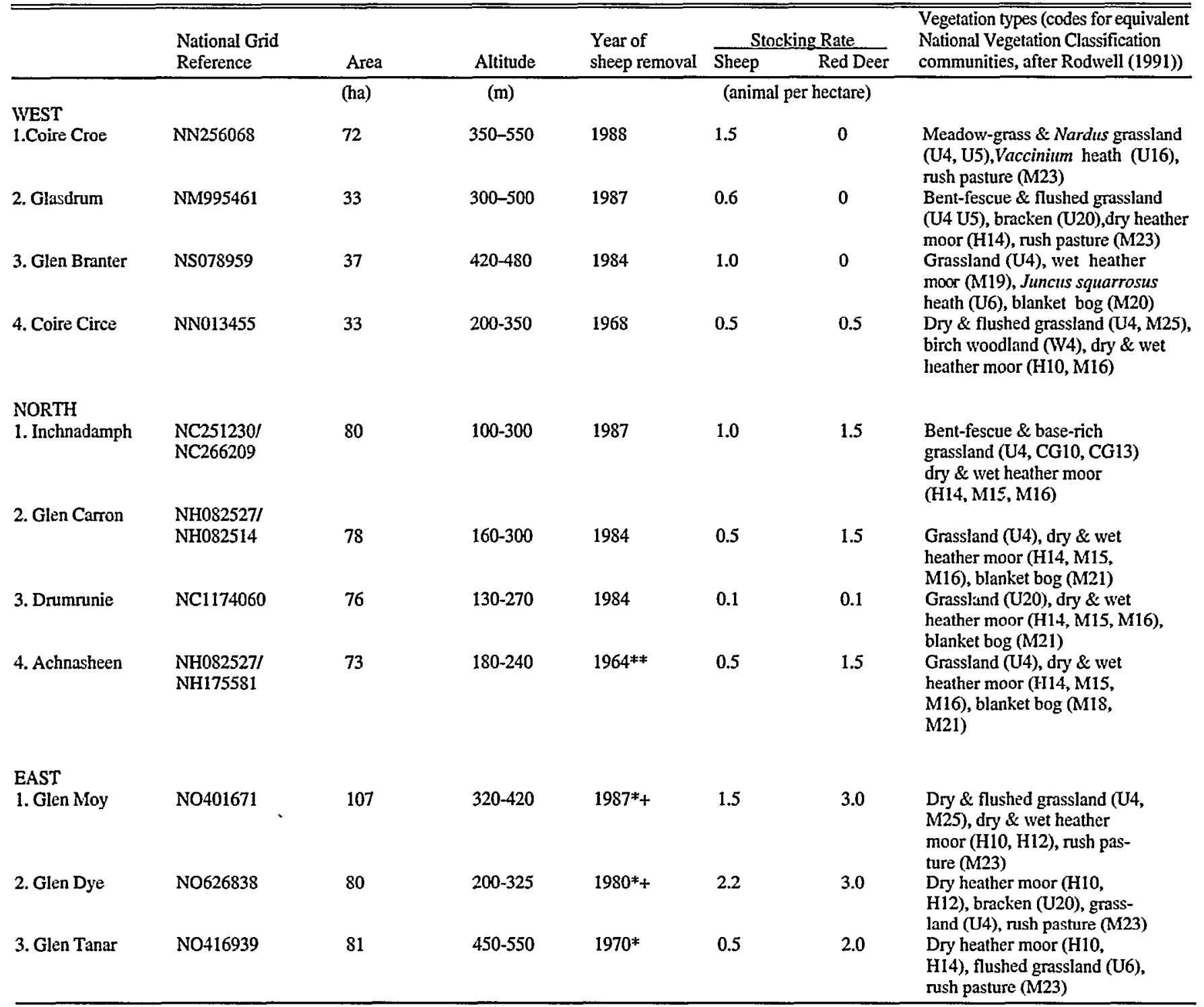

tgrazing reduced from all year to summer only.

theather buming carried out every 8-12 years on both reduced-sheep and control areas.

** heuther buming carried out every $8+12$ years on the reduced-sheep part of the site only.

Aerial photographs at scales between 1:10000 to 1:25000, taken as close as possible to the date when sheep were removed, were examined to check that there were no differences in the appearance of the vegetation between each paired control and reduced-sheep area. Comparability of soils, parent materials, underlying geology, and physiography were assessed during site inspections by soil surveys who dug trial soil pits and examined auger samples taken from below the main vegetation types at each site. Details of current and past management practices (Table 1) were obtained from farmers, gamekeepers, estate managers, and land owners. A number of potential paired sites were rejected at this stage, because reduced-sheep and control areas were too dissimilar.

\section{Sampling Procedure}

At each site broad vegetation types were first defined, using the cover of a number of common upland plant species (Table 2).
Detailed quantitative descriptions of the vegetation structure within each vegetation type, along with assessments of activity by grazing animals were carried out in $2 \mathrm{~m}$ radius circular plots. This plot size and shape was chosen to obtain an adequate sample of vegetation and ungulate dung (Batchelor 1973), while being small enough to allow estimation of the main structural components of the vegetation by eye. Plots were located by constrained random sampling, along parallel transects, which approximately followed the contours of the hillside. The approximate starting point of each transect was chosen to ensure adequate coverage of the whole site, while the exact starting point was determined by taking a random number of paces from the lower site boundary or the previous transect. Floristic composition in each circular plot was assessed using a randomly placed $1 \mathrm{~m}^{2}$ quadrat. Between 6 and 18 plots were sampled within each vegetation type on both the reduced-sheep and control areas at each site, except in a few cases where only 4 or 5 plots could be sampled due to a vegeta- 


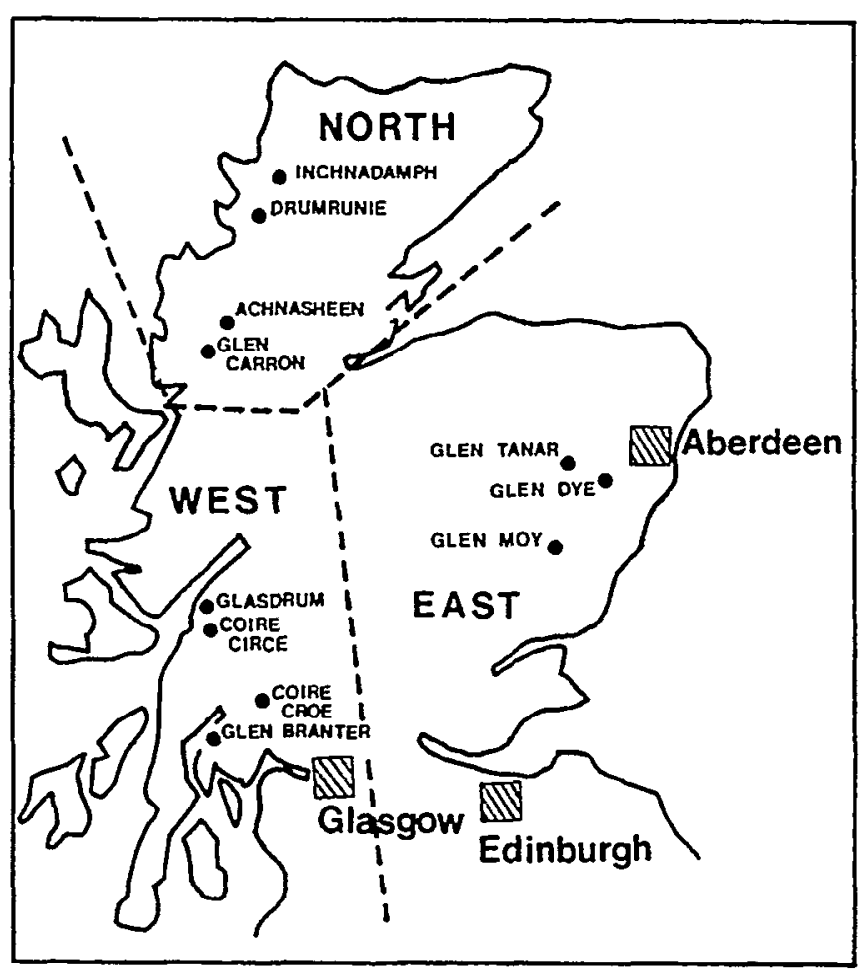

Fig. 1. Location of the study sites and the main bioclimatic zones.

tion type having a very limited extent. Each site was sampled once in early summer 1989 and again in early summer 1990.

\section{Floristic Composition of Vegetation}

Species composition was recorded in the $1 \mathrm{~m}^{2}$ quadrat within each circular plot. Nomenclature followed Clapham et al. (1987) for vascular plants and Smith (1978) for mosses, although species in some genera (e.g. Festuca spp., Carex spp.) were not distinguished if they were difficult to identify when heavily grazed (Table 3). At each site the number of plant species in the reducedsheep area was compared with that in the control area by taking an equal number of plots differed from each vegetation type and using chi-square tests; where the number of plots between the 2 areas, excess samples were chosen randomly and excluded. Cover estimates for all species present were made on the Domin scale (Kershaw and Looney 1985). Cover estimates were grouped by site and vegetation type; because these data were obtained using an ordinal scale, it was often not possible to transform them into a normal distribution. Therefore differences between control and reduced-sheep areas for each vegetation type, on each site, were examined using the Mann-Whitney $U$ statistic given in the SAS NPARIWAY procedure (SAS 1982).

\section{Sward Structure}

The identity, arrangement and height of the sward components in the $2 \mathrm{~m}$ radius circular plots were described quantitatively using 9 vegetation layer classes (trees and shrubs, ferns, rushes, dwarf shrubs, grasses, herbs, mosses, algae, and litter). The extent of each distinct 'combination' of the layer classes was estimated and the height of each layer within each combination measured (Grant 1993). Bar diagrams were used to show the mean extent of vegetation layers at selected height intervals, for reduced-sheep and control areas at each site. The extent of a vegetation layer within an individual vegetation type was often not normally distributed and difficult to transform to normality. Therefore differences in the extent of the most common layer combinations at each site, within each vegetation type, were again compared using Mann-Whitney U-tests. The height of structural layers was, however, normally distributed. The height of individual structural layers in each plot was calculated by weighting the measured height according to the extent of the layer combination in which the layer occurred and differences between reduced-sheep and control plots were examined using t-tests. The mean height of the overall sward in each plot was calculated in a similar way, using the height of the uppermost layers(s).

The patch size of the various types was measured by walking 2 sets of transects at each site (Phillips 1989, Grant 1993) in summer 1990. Transects were aligned along compass bearings which ran parallel and perpendicular to the contours. The number of paces taken to cross each patch was recorded, converted to metres and corrected for slope. The data were generally skewed, most vegetation types consisting of a few large patches and many small ones and so were normalized using a log transform (base $e$ ). The transformed data were then examined using the SAS General Linear Model (GLM) procedure (SAS 1982) to do a twoway analysis of variance with interactions. Patch sizes from the 2 sets of transects (termed 'length' along the contours and 'breadth' across the contours) were modeled separately, using vegetation type and grazing regime (reduced-sheep versus control) as class variables, with a vegetation type $X$ grazing regime interaction term, for each site.

Table 2. Key to the vegetation types used in the study.

\begin{tabular}{|c|c|c|}
\hline \multirow{2}{*}{$\begin{array}{l}\text { Vegetation Type } \\
\text { Grassland }\end{array}$} & \multicolumn{2}{|c|}{ Cover of Key Species/Genera } \\
\hline & $\begin{array}{l}>50 \% \\
<20 \% \\
<20 \%\end{array}$ & $\begin{array}{l}\text { Graminoids } \\
\text { Dwarf shrub } \\
\text { Sphanum spp. }\end{array}$ \\
\hline Base-rich grassland & $\begin{array}{l}\text { as gras } \\
>20 \%\end{array}$ & $\begin{array}{l}\text { Ad but with:- } \\
\text { Thymus drucei, Lotus conziculatus } \\
\text { or Dryas octopetala }\end{array}$ \\
\hline Bracken & $>10 \%$ & $\begin{array}{l}\text { as grassland but with:- } \\
\text { Pteridium aquilinum }\end{array}$ \\
\hline Dry heather moor & $\begin{array}{l}>20 \% \\
<20 \%\end{array}$ & $\begin{array}{l}\text { Dwarf shrub } \\
\text { Sphagnum spp., Scirpus cespitosus } \\
\text { or Molinea caerulea }\end{array}$ \\
\hline Wet heather moor & $\begin{array}{l}>20 \% \\
>20 \%\end{array}$ & $\begin{array}{l}\text { Dwarf shrub } \\
\text { Sphagnum spp., S. cespitosus or } M \text {. caerulea }\end{array}$ \\
\hline $\begin{array}{l}\text { Juncus squarrosus } \\
\text { heath }\end{array}$ & $\begin{array}{l}>30 \% \\
<20 \% \\
<20 \%\end{array}$ & $\begin{array}{l}\text { J. squarrosus } \\
\text { Sphagnum spp. } \\
\text { Eriophorum spp. }\end{array}$ \\
\hline Blanket bog & $\begin{array}{l}>20 \% \\
<20 \% \\
>10 \%\end{array}$ & $\begin{array}{l}\text { Sphagnum spp. } \\
\text { Dwarf shrub } \\
\text { Eriophorum spp. }\end{array}$ \\
\hline Flushed grassland & $\begin{array}{l}>20 \% \\
>50 \%\end{array}$ & $\begin{array}{l}\text { Sphagnum spp. } \\
\text { or } \\
\text { Carex spp., M. caerulea or Myrica gale }\end{array}$ \\
\hline Rush pasture & $\begin{array}{l}>30 \% \\
>20 \%\end{array}$ & $\begin{array}{l}\text { Juncus spp. } \\
\text { Sphagntm spp. }\end{array}$ \\
\hline
\end{tabular}


Table 3. Median cover scores (Domin scale) for the main plant species on the control area of each site. Suffix indicates where the cover on the reduced-sheep treatment was significantly greater $(+)$ or less $(-)$ in one or more vegetation types; Mann-Whitney $U$-test, $\mathbf{P}<0.05$.

\begin{tabular}{|c|c|c|c|c|c|c|c|c|c|c|c|c|}
\hline \multirow[b]{2}{*}{ Species } & \multirow{2}{*}{ Site } & \multicolumn{2}{|c|}{ West } & \multirow[b]{2}{*}{3} & \multirow[b]{2}{*}{4} & \multicolumn{2}{|c|}{ North } & \multirow[b]{2}{*}{3} & \multicolumn{2}{|c|}{ East } & \multirow[b]{2}{*}{2} & \multirow[b]{2}{*}{3} \\
\hline & & 1 & 2 & & & 1 & 2 & & 4 & 1 & & \\
\hline \multicolumn{13}{|l|}{ Dwarf shrubs } \\
\hline Calluna vulgaris L. Hull & & & $1^{+}$ & 9 & $8^{+}$ & 9 & 6 & 8 & 6 & $9^{+}$ & 9 & 6 \\
\hline Erica tetralix L. & & & & 2 & & 3 & $5^{-}$ & 5 & $5^{+}$ & & & \\
\hline Vaccinium myrillus $\mathrm{L}$. & & $9^{+}$ & 5 & 6 & 4 & & & & & 5 & & 2 \\
\hline Anthoxanthum odoratum $\mathrm{L}$. & & $8^{-}$ & 6 & 6 & 2 & 5 & & & & 2 & 4 & \\
\hline Carex L. & & $5^{-}$ & $5^{+}$ & 1 & 2 & 4 & $5^{+}$ & 3 & 5 & 4 & 2 & $2^{+}$ \\
\hline Deschampsia flexuosa (L.) Trin. & & $5^{-}$ & 4 & $5^{+}$ & $0^{+}$ & 4 & $0^{+}$ & & $0^{+}$ & $5^{-}$ & 3 & 3 \\
\hline Festuca L. & & 6 & 8 & 5 & $8^{-}$ & & $0^{-}$ & $0^{-}$ & & & 5 & \\
\hline Molinia caerulea (L.) Moench. & & & & & 3 & $3^{-}$ & $6^{-}$ & 5 & $6^{-}$ & & & \\
\hline Nardus stricta $\mathrm{L}$ & & 8 & 8 & 5 & $4^{-}$ & & 2 & & $2^{+}$ & 7 & 3 & 5 \\
\hline Juncus squarrosus L. & & 7 & $5^{+}$ & 4 & & & & & & $4^{-}$ & $3^{-}$ & 5 \\
\hline Luzula D.C. & & $2^{-}$ & $2^{+}$ & 4 & & & & & & 3 & 5 & \\
\hline Scirpus caespitosus L. & & & & & $5^{-}$ & 5 & $8^{+}$ & $8^{-}$ & 8 & & & \\
\hline \multicolumn{13}{|l|}{ Herbs } \\
\hline Galium saxatile (L.) Hudson & & 6 & 5 & & $3^{+}$ & 4 & 0 & & 9 & 5 & 5 & \\
\hline Narthecium ossifragum $\mathrm{L}$. & & & & 2 & $4^{-}$ & 5 & 7 & 4 & $7^{+}$ & 7 & & \\
\hline Polygala serpyllifolia Weihe & & & 3 & & $3^{-}$ & $1^{-}$ & 2 & & & & & \\
\hline Potentilla erecta (L.) Rauschel & & 7 & 8 & & 6 & 5 & 1 & 3 & $2^{+}$ & 3 & 2 & \\
\hline \multicolumn{13}{|l|}{ Ferns } \\
\hline Pteridium aquilinum (L.) Kuhn & & & 8 & & & 7 & & 7 & & & 8 & \\
\hline Sphagnum L. & & $1^{+}$ & & $7^{-}$ & 8 & & $8^{+}$ & $6^{-}$ & $3^{-}$ & 3 & & 2 \\
\hline \multicolumn{13}{|l|}{ Lichens } \\
\hline Cladonia (Hill) Web. & & & & 3 & & 3 & 2 & $0^{+}$ & $3^{-}$ & & & $3^{-}$ \\
\hline
\end{tabular}

\section{Herbivore Dung}

Use of plots by sheep, red deer, and roe deer was assessed from dung. Fresh pellet groups (defined as 10 or more unweathered pellets lying close together) were classified as sheep, red deer, roe deer, or unidentified (Welch et al. 1990) and the number within each circular plot was counted. Unidentified pellets usually comprised less than $10 \%$ of the total. Pellet groups at the edge of a plot were counted only if more than half the pellets fell inside the plot. Where dung was weathered or the amount present was insufficient to class as a pellet group, it was given the arbitrary value of half a pellet group, to distinguish areas with a small amount of dung from those where none was found. Pellet group counts for sheep, red deer, and total ungulate (including roe deer and unidentified) from control and reduced-sheep areas at each site were compared using Mann-Whitney U-tests, since the data rarely conformed to a normal distribution. The repeatability of pellet group counts between years was compared by calculating in-traclass correlation coefficients $\left(r_{1}\right)$ for the reduced-sheep and control data (Snedecor and Cochran 1967). Numbers of roe deer and unidentified pellet groups were too few to analyze separately.

The droppings of mountain hare and rabbit do not usually occur in discrete groups, but tend to be scattered. It was time-consuming to count them, so numbers of droppings were estimated on an ordinal scale where: $1-10$ pellets $=1,11-25=2,26-50=3$, $51-100=4,>100=5$. Differences between scores on the reducedsheep and control areas at each site were examined using MannWhitney U-tests. Droppings of red grouse were recorded as present or absent and the frequency on reduced-sheep and control areas compared using chi-square tests. 


\section{Vole Signs}

The activity of voles was assessed from signs (Hayne and Thompson 1965, Lidicker 1973, Tapper 1979, Village and Myhill 1990 ), in the same plots where vegetation and dung were measured. Vole runs were searched for by gently parting the lower layers of vegetation and tracing out any runs that were found. A vole run was recorded as present if at least $1 \mathrm{~m}$ was found in a plot and less than $1 \mathrm{~m}$ was recorded as trace. Fresh droppings, grass, and rush clippings were also noted. Chi-square tests were used to compare the proportion of plots containing runs, droppings, and clippings between the reduced-sheep and control areas. Since droppings and clippings were only found at 5 sites, the relationship between vole signs and vegetation structure was investigated using only the data on vole runs. The difference in the frequency of vole runs between the reduced-sheep and control areas at each site, was plotted against the difference in mean vegetation height.

To examine the relationship between vole runs and vegetation height in more detail, plots from all sites were grouped into vegetation height classes ( $2 \mathrm{~cm}$ intervals); the frequency of plots containing vole runs in each height interval (y) was plotted against the mid-points of the height intervals $(x)$ and a linear regression calculated. To examine whether vole runs were associated with particular sward components, vole run frequency, the mean height of each layer, and the percentage of plots containing tussocks were calculated, by vegetation type and grazing regime, and examined by Principal Components Analysis. The frequency of vole runs was then compared with the resulting principal component scores in a multiple regression. Simple linear regressions of the frequency of vole runs against individual principal component scores were also calculated.

\section{Results}

\section{Floristic Composition}

There were a number of significant differences in the Domin cover scores of individual plant species between the reducedsheep and control areas (Table 3). Dwarf shrubs showed few differences, although Calluna vulgaris L. Hull had higher cover scores $(\mathrm{P}<0.05)$ on the reduced-sheep areas at 3 sites. Differences in cover scores were found more frequently amongst the grasses; the cover of Agrostis L. spp., Festuca L. spp., and Molinia caerulea $(\mathrm{L}$.) Moench. were usually greater on the control areas

Table 4. Comparison of the number of plant species on control (C) and reduced-sheep (R) areas.

\begin{tabular}{lllllll}
\hline \hline $\begin{array}{c}\text { Bioclimatic Site } \\
\text { zone }\end{array}$ & $n$ & \multicolumn{2}{c}{ Number of species } & Chi-square value P \\
\cline { 2 - 5 } West & Coire Croe & 45 & 60 & 65 & 0.20 & 0.66 \\
& Glasdrum & 45 & 85 & 77 & 0.40 & 0.53 \\
& Glen Branter & 30 & 46 & 39 & 0.97 & 0.45 \\
& Coire Circe & 45 & 80 & 62 & 2.28 & 0.13 \\
North & Inchnadamph & 51 & 84 & 91 & 0.28 & 0.60 \\
& Glen Carron & 35 & 55 & 59 & 0.14 & 0.71 \\
& Drumrunie & 41 & 50 & 50 & 0.00 & 1.00 \\
& Achnasheen & 39 & 53 & 53 & 0.00 & 1.00 \\
East & Glen Moy & 45 & 57 & 55 & 0.04 & 0.85 \\
& Glen Dye & 43 & 62 & 65 & 0.07 & 0.79 \\
& Glen Tanar & 48 & 71 & 61 & 0.76 & 0.38 \\
\hline
\end{tabular}

$(\mathrm{P}<0.05)$, while the cover of Carex L. spp. and Deschampsia flexuosa (L.) Trin. tended to be higher on reduced-sheep areas $(P<0.05)$. No consistent pattern emerged for the cover of the main rush and herb species. For mosses, trends differed among species. Cover scores for Sphagnum L. spp., Racomitrium lanuginosum (Hedw.) Brid. and Hypnum cupressiforme Hedw. were most often higher on the control areas, while those of Rhytidiadelphus (Hedw.) Warnst spp. tended to be higher on the reduced-sheep areas $(\mathrm{P}<0.05)$; however the opposite trends were also observed for most of these species on at least 1 site. Overall, there was no consistent difference $(\mathrm{P}<0.05)$ in the number of species recorded on reduced-sheep and control areas (Table 4).

\section{Sward Structure}

Vegetation was usually taller $(\mathrm{P}<0.05)$ on reduced-sheep areas, most notably at 4 sites in the western Highlands and 1 site in the northern Highlands (Table 5). At sites where sheep had been removed for over 5 years, differences were most pronounced in the dwarf shrub, grass, and moss layers (Fig. 2a-c). At 2 sites where sheep removal had occurred 1-3 years before the study
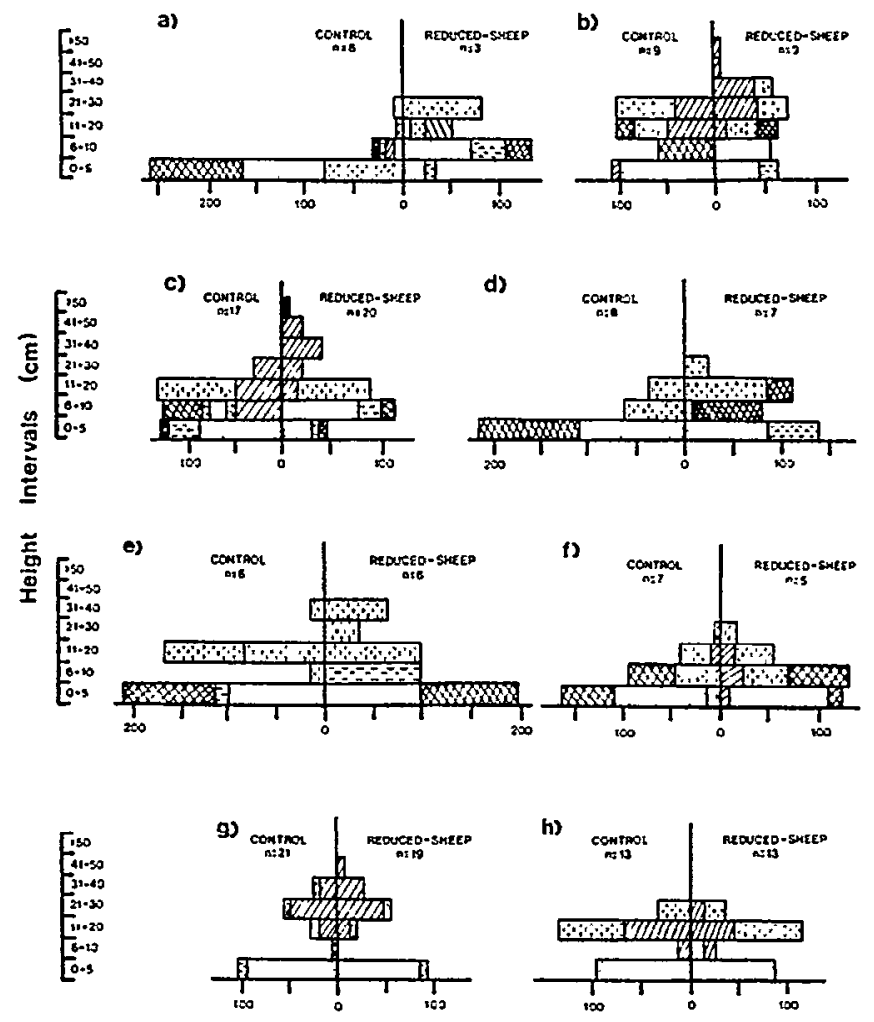

Extent $(\%)$

Fig. 2. Bar charts showing the extent of each sward component or layer at selected height intervals; the contrasts between the control and reduced-sheep areas in these 8 vegetation types were typical of those seen in the study overall (\% figures are mean values for ' $n$ ' samples) : a) grassland, GIen Branter; b) dry heather moor, Drumrunie; c) wet heather moor, Coire Circe; d) meaadow-grass grassland, Coire Croe; e) rush pasture, Coire Croe; f) grassland, Glen Carron; g) dry heather moor, Glen Tanar; h) wet heather moor, Glen Carron. Key to layer shadings: tree/shrub - solid; rush - vertical dashes and dots; dwarf shrub - diagonal hatching; grass - vertical dashes; moss - stippled; herbs - cross hatching; litter horizontal dashes. 
Table 5. Mean height of vegetation layers $(\mathrm{cm})$ on control areas, with heights on reduced-sheep areas where significantly taller; values in brackets indicate where a layer was taller on the control area.

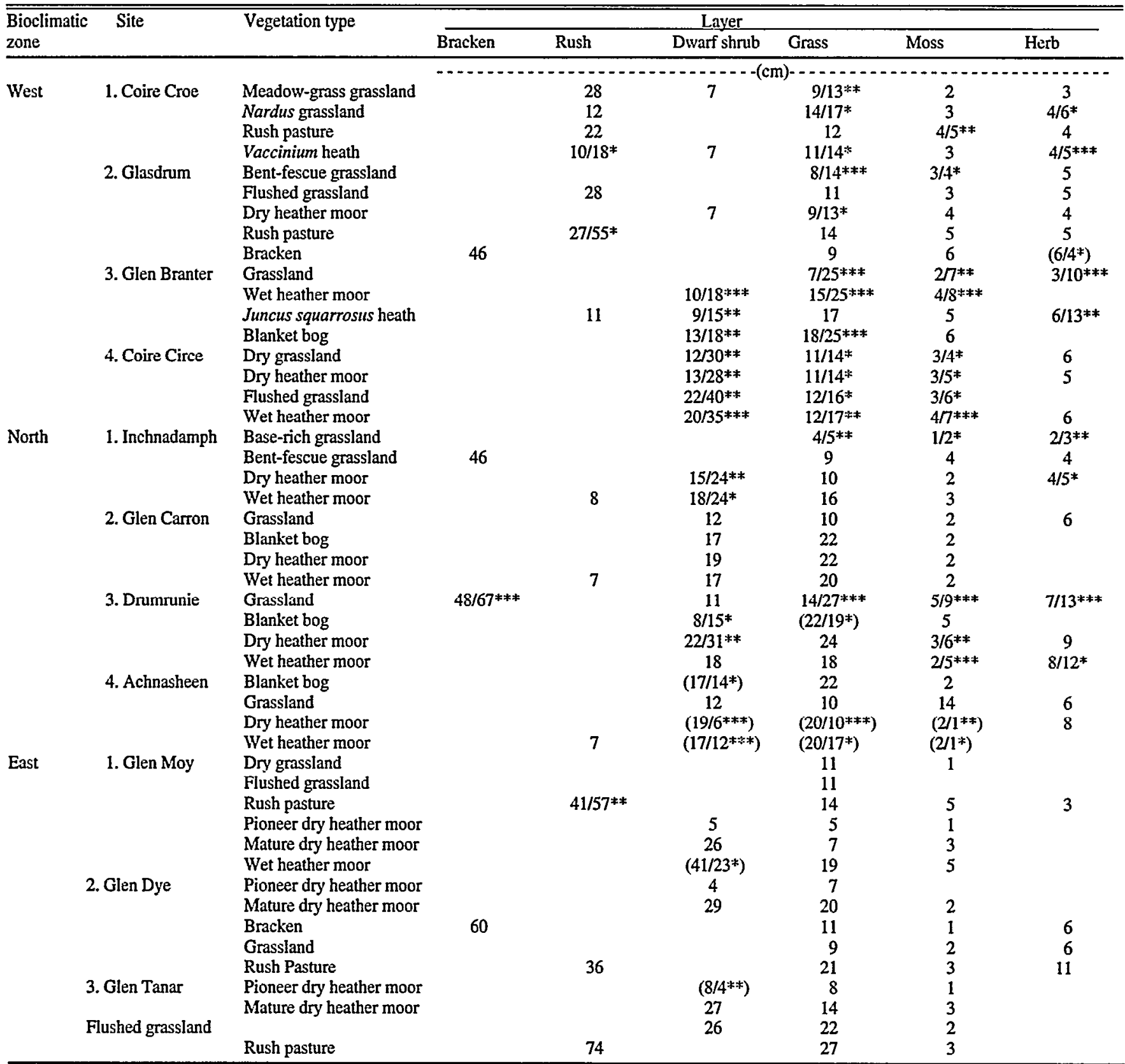

$*, * *, * * *$ Significant at the $0.05,0.01$ and 0.001 levels respectively (t-test).

began, differences were mostly confined to grass, herb, and rush layers (Fig. 2d-e). However at the 6 remaining sites there were few differences in the height of sward components (Fig. 2f-h). Analysis of patch size showed few consistent differences between reduced-sheep and control areas when all vegetation types were grouped together (Table 6 , grazing term). However patches of heather moor tended to be larger and patches of grassland smaller on reduced-sheep areas at western and some northern sites, resulting in an interaction $(P<0.05)$ between vegetation type and grazing regime (Table 6 , interaction term).

\section{Herbivore Dung}

There were usually fewer sheep pellet groups on reduced-sheep areas than on controls $(P<0.05)$, although sheep did sometimes stray onto areas from which they had been removed (Fig. 3a). Nevertheless, sheep pellet group counts were largely repeatable between years (intraclass correlation for control $r_{1}=0.78, P<0.01$; reduced-sheep $\left.\mathrm{r}_{\mathrm{I}}=0.59, \mathrm{P}<0.01\right)$. Red deer pellet groups were less numerous than those of sheep at most sites (Fig. 4b). More red deer pellets were found on control areas than on reduced-sheep areas at western sites, although the differences were not always significant. Red deer pellet counts were repeatable between years on reduced-sheep areas $\left(\mathrm{r}_{1}=0.70, \mathrm{P}<0.01\right)$, but more variable on control areas $\left(r_{I}=0.30, P>0.05\right)$. Total ungulate pellet group counts were repeatable between years on both control $\left(r_{l}=0.69\right.$, $\mathrm{P}<0.01)$ and reduced-sheep $\left(\mathrm{r}_{\mathrm{I}}=0.84, \mathrm{P}<0.001\right)$ areas. Again, there were usually more pellet groups on the control areas, especially at western sites (Fig. 4c). 
Mountain hare and rabbit droppings were present at 6 sites, but a consistent difference in pellet scores occurred only at the Glen Branter site, where there were more hare droppings on the reduced-sheep area than the control area in both years $(\mathrm{P}<0.05)$. Red grouse droppings were present in small amounts at most sites, but there was a difference only at the Achnasheen site, where there were more droppings on the reduced-sheep area in both years $(\mathrm{P}<0.05)$.

\section{Vole Signs}

Vole runs were found at all 11 sites and in most vegetation types. The proportion of plots containing vole runs at each site was similar in both years. Runs were more frequent in plots on reduced-sheep than on control areas at 4 sites in the western Highlands and at 1 site in the northern Highlands (Table 7). Including records of trace with presence scores did not change the results. Where they were present, fresh droppings and clippings showed the same difference between grazing regimes (Table 7). The difference in the frequency of vole runs between reduced-sheep and control areas was correlated with the difference in sward height at the same sites (Fig. 4). The regression equation relating vole run frequency $(y)$ and sward height $(x), y=$ $53 \log _{10} x-20\left(n=20 ; r^{2}=0.84\right)$, intercepted the $x$ axis at $5 \mathrm{~cm}$, indicating that runs were found only when the sward was taller than this.

Principal components analysis of layer height and tussock frequency (Table 8a) explained $87 \%$ of the variation in vole run fre-
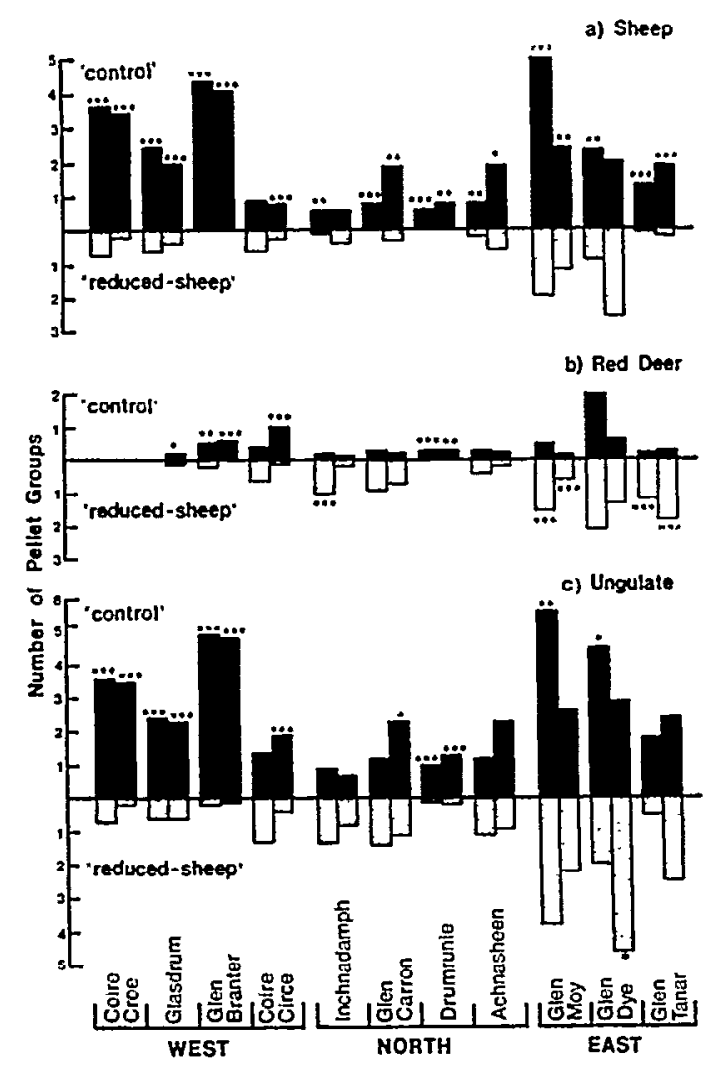

Fig. 3. Mean number of pellet groups on all 11 sites in 1989 (lefthand bars) and 1990 (right-hand bars). *,**, ***, indicate the significance of differences between the control and reduced-sheep areas at the $0.05,0.01$ and 0.001 levels respectively.

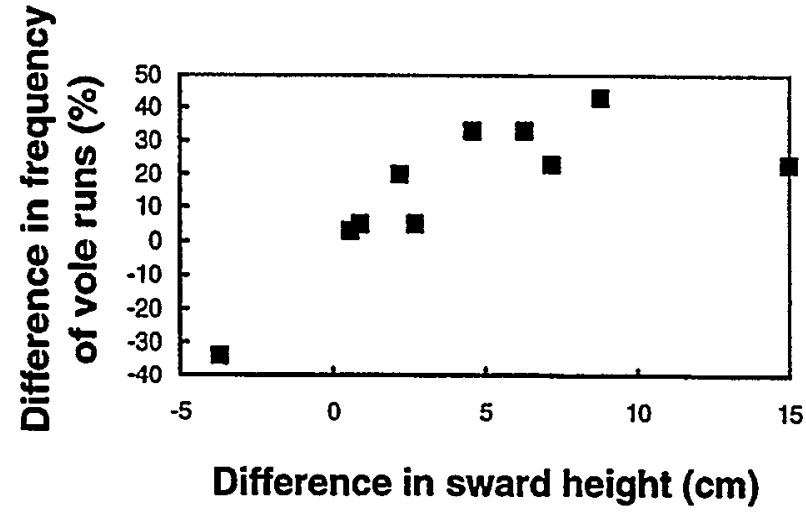

Fig. 4. Difference in sward height versus the difference in the frequency of vole runs between the reduced-sheep and control areas at each site; positive values indicate that the sward was taller and vole runs were more frequent on the reduced-sheep versus the control area, negative values indicate a difference in the opposite direction.

quency in terms of 4 principal components. These were interpreted as: i) tall grass, moss, rush, and litter layers, with tussocks present, ii) tall dwarf shrub layer, with some moss but few rushes, iii) tussocks without litter and iv) tussocks with litter. Regressions of vole run frequency on the scores for these 4 principal components showed that only the scores for the first 2 principal components had significant explanatory value (Table $8 b$ ); the first principal component was the best single explanatory variable (Table $8 \mathrm{c}$ ).

\section{Discussion}

In previous studies where sheep have been removed from rangeland in upland Britain, initial rapid increases in the height of vegetation have usually been followed in successive years by gradual increases in the cover of dominant species, particularly dwarf shrubs such as Calluna vulgaris, with a decline in the cover of most grasses and herbs (Jones 1967, Ball 1974, Rawes 1981, Marrs et al. 1988). In the present study, sheep removal appears to have resulted in similar vegetation changes at 5 of the sites. Although the differences in species cover and composition found in the present study are less marked than in some earlier work, this could be partly due to differences in methods. For example, we stratified sampling within vegetation types, to avoid confusing differences due to small variations in edaphic conditions with grazing-induced differences. Thus, what previous authors recorded as changes in species composition, could have been recorded by us as apparent changes in the extent of different vegetation types. In particular, the overall tendency for patches of heather moor to be larger and grassland to be smaller on reducedsheep compared to control areas suggests that, where soils are relatively freely drained, a reduction in grazing pressure leads to the expansion of dwarf shrub-dominated vegetation at the expense of grassland, until patches eventually coalesce to form a continuous sward. Presumably when grazing pressure is increased this process is reversed, as in habitat fragmentation (Wiens 1989).

The removal of sheep apparently had little effect on either the composition or structure of the vegetation at 6 sites, even where 
Table 6. Analysis of variance for vegetation patch size (using two-class SAS General Linear Model procedure).

\begin{tabular}{|c|c|c|c|c|c|c|c|}
\hline Site & $\begin{array}{l}\text { Summary of differences on } \\
\text { reduced-sheep relative to } \\
\text { control areas. }\end{array}$ & \multicolumn{5}{|c|}{ Significance levels } & \\
\hline Glasdrum & $\begin{array}{l}\text { Dry heather moor patches larger, } \\
\text { grassland patches smaller. }\end{array}$ & $<0.001$ & NS & NS & $<0.001$ & NS & NS \\
\hline Coire Circe & $\begin{array}{l}\text { Wet heather moor patches larger, } \\
\text { grassland patches smaller. }\end{array}$ & $<0.001$ & NS & $<0.001$ & $<0.001$ & 0.025 & NS \\
\hline $\begin{array}{l}\text { North } \\
\text { Inchnadamph }\end{array}$ & $\begin{array}{l}\text { Dry heather moor patches larger, } \\
\text { grassalnd patches smaller. }\end{array}$ & 0.02 & NS & 0.008 & NS & NS & NS \\
\hline Achnasheen & $\begin{array}{l}\text { Wet heather moor patches larger, } \\
\text { grassland patches smaller. }\end{array}$ & $<0.001$ & NS & NS & $<0.001$ & NS & 0.005 \\
\hline \multicolumn{8}{|l|}{ East } \\
\hline Glen Moy & $\begin{array}{l}\text { Patches of pioneer and mature } \\
\text { heather moor and grassland larger. }\end{array}$ & $<0.001$ & NS & NS & $<0.001$ & 0.004 & NS \\
\hline Glen Dye & $\begin{array}{l}\text { Patches of all vegetation types } \\
\text { larger. }\end{array}$ & $<0.001$ & NS & NS & $<0.001$ & 0.015 & NS \\
\hline Glen Tanar & No consistent differences. & $<0.001$ & NS & NS & $<0.001$ & NS & NS \\
\hline
\end{tabular}

sheep had been absent for many years. At these 6 sites, red deer pellets on the reduced-sheep areas were at least as numerous as on the respective control areas, resulting in little difference in the total amount of ungulate dung between grazing regimes. Although direct counts of red deer were not made, the standing crop of dung gives a good indication of feeding dispersion for red deer on open rangeland (Charles et al. 1977, Mitchell et al. 1983, Welch et al. 1990). Obviously the dung counts made during this two-year study may not always represent longer term patterns of site use particularly well, for example at Coire Circe where a recent break in a fence had allowed some animals into the reduced-sheep area for a short period before the start of the study. Also, potential differences in the rate of decomposition precluded any quantitative comparison of dung data between the different sites. Nonetheless, this was unlikely to invalidate comparisons between control and reduced-sheep areas within sites. Hence we suggest that the removal of sheep at these 6 sites has been followed by increased use of the rangeland by red deer, which has

Table 7. Differences in the frequency of vole signs between control (C) and reduced-sheep (R) areas from chi-square tests.

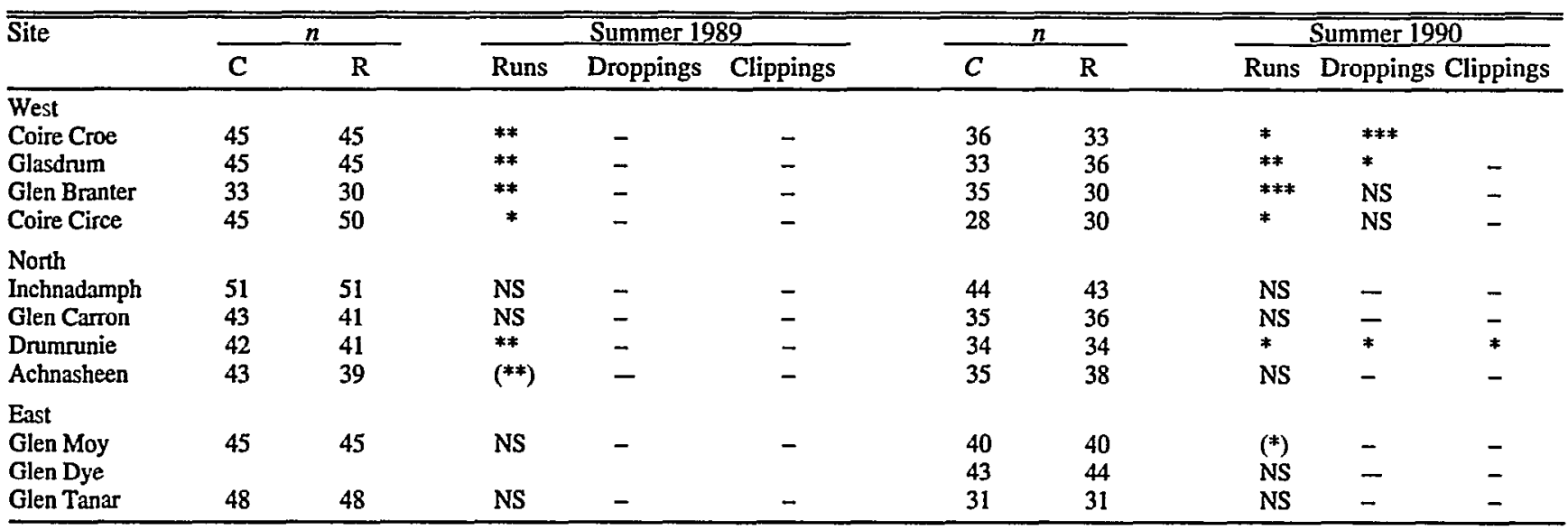

****** Significant at the $0.05,0.01$ and 0.001 levels respectively; more signs were found on the reduced-sheep areas in all case, except where indicated by brackets.

indicates signs were absent or too infrequent to test. 
Table 8. Analysis of the relationship between vole runs and sward structure, grouping the data (from 1989) by site and grazing regime. (a) Principal components analysis of mean layer height and tussock frequency. (b) Results of a multiple regression of vole run frequency on the principal component scores of the first 4 axes. (c) Results of linear regressions of vole run frequency on the component scores for axes 1 and 2.

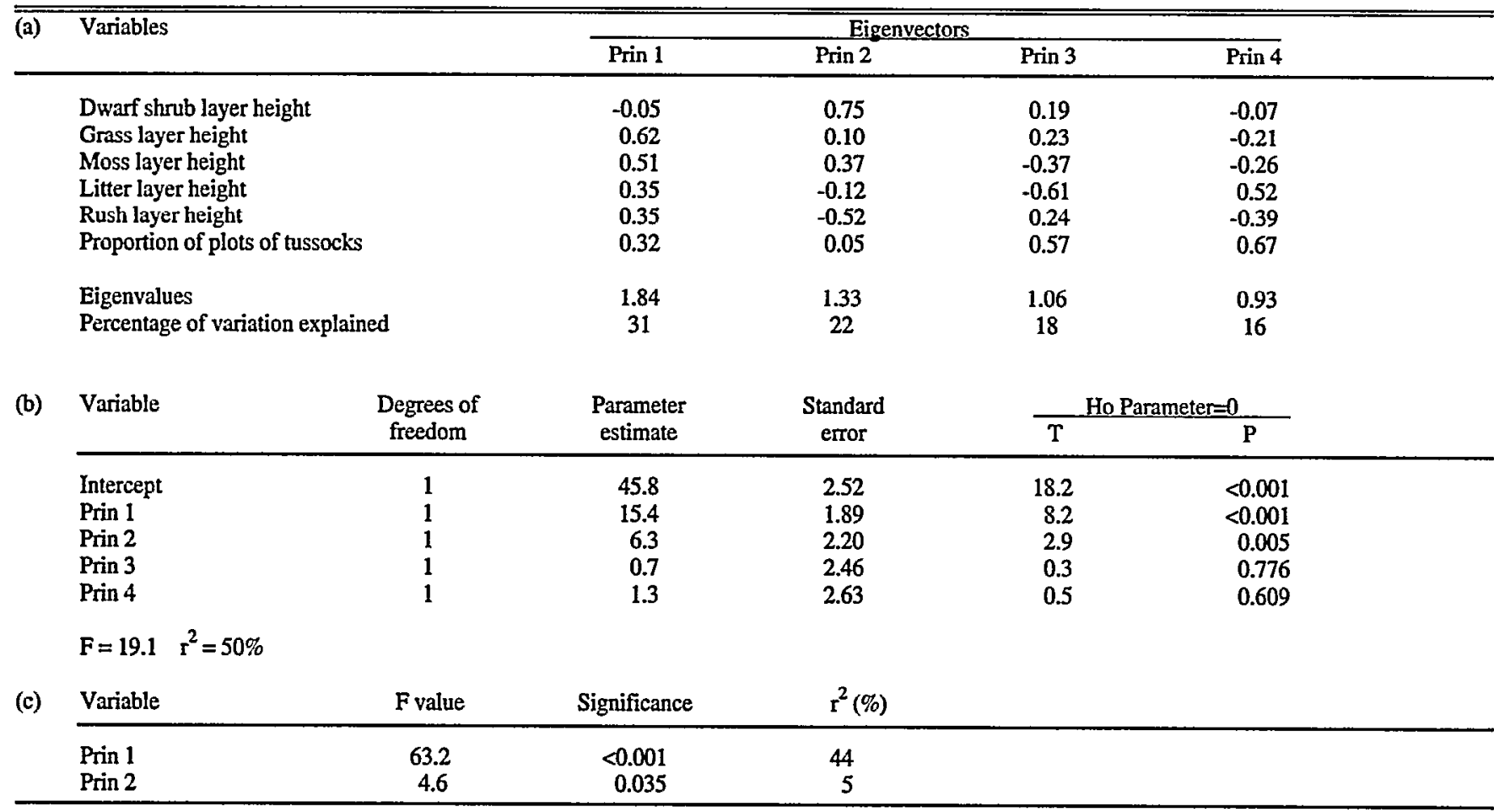

suppressed any significant changes in vegetation composition or structure. The continued practice of rotational heather burning at most of these sites is also likely to have helped maintain the composition and structure of heather-dominated vegetation (Gimingham 1972).

There are similar findings in previous work. The floristic composition of species-rich grassland on the Isle of Rhum changed very little following the removal of sheep and cattle, due to increased red deer grazing (Ball 1974). In north-east Scotland few differences were detected in heather moorland grazed by an equal biomass of sheep or red deer (Welch 1984a, Welch 1984b), or after red deer replaced sheep (Grant et al. 1981).

\section{Voles}

The results suggest that vole activity increased following the removal of sheep grazing, at the 5 sites where vegetation height increased. The effect appears to have been more pronounced the taller the resulting sward. A number of studies have shown the importance of vegetation cover to microtine populations (Taitt et al. 1981, Taitt and Krebs 1983, Kotler et al. 1988). In the present study, it appeared that the amount of cover above a height of 5 $\mathrm{cm}$ had a large influence on vole activity. Tall grass and moss layers presumably provide good cover, along with food in the case of grass. Tussocks and tall rushes are probably important because they provide good sites for tunneling and nest building. The dwarf shrub layer may be less important because it provides adequate cover but is of little food value.

\section{Implications for Other Herbivores}

The overall lack of differences in dropping of hares, rabbits, and red grouse between reduced-sheep and control areas suggests that removal of sheep had little effect on these species, probably because red deer grazing and heather burning prevented the vegetation from changing at most of the sites where signs of these species were found. However the changes in vegetation seen at the other study sites following the removal of sheep are likely to be important to wild herbivores (Miller et al. 1970, Hewson 1976, Savory 1986, Watson et al. 1987).

\section{Conclusions}

In accordance with previous work, we conclude that reduced sheep grazing can quickly result in taller vegetation, which may be followed by a slower shift from grassy vegetation to dwarf shrubs and trees on unburned rangeland. Such changes in vegetation structure and composition will affect other wild herbivores; in particular the abundance of voles is likely to increase as the height of grassy vegetation increases above $5 \mathrm{~cm}$. However, removing sheep from rangland in the Scottish Highlands is likely to have little effect on vegetation in areas where there are appreciable numbers of red deer or where heather burning is continued.

\section{Literature Cited}

Ball, M.E. 1974. Floristic changes on grasslands and heaths on the Isle of Rhum after a reduction or exclusion of grazing. J. Environ. Manage. 2:299-318

Batchelor, C.L. 1973. Estimation of population density changes. Forest Research Institute Symposium 14:8-17, New Zealand Forest Service, New Zealand. 
Birse, E.L. 1971. Assessment of Climatic Conditions in Scotland: Bioclimatic Sub-Regions. Macaulay Institute for Soil Research, Aberdeen.

Charles, W.N., D. McCowan, and K. East. 1977. Selection of upland swards by red deer (Cervus elaphus L.) on Rhum. J. Appl. Ecol. 14:55-64.

Clapham, A.R., T. G. Tutin, and D.M. Moore. 1987. Flora of the British Isles. Cambridge Univ. Press, Cambridge.

Gimingham, C.H. 1972. Ecology of Heathlands. Chapman and Hall, Oxford.

Grant, S.A. 1993. Resource description: vegetation and sward components, p 145-155. In: A. Davies, R.D. Baker, S.A. Grant and A.S. Laidlaw (eds.), Sward Measurement Handb. Brit. Grassl. Soc., Reading.

Grant, S.A., G.R. Bolton, and L. Torvell. 1985. The responses of blanket bog vegetation to controlled grazing by hill sheep. J. Appl. Ecol. 22:739-751.

Grant, S.A., W.J. Hamilton, and C. Souter. 1981. The response of heather-dominated vegetation in north-east Scotland to grazing by red deer. J. Ecol. 69:189-204.

Hayne, D.E. and D.Q. Thompson. 1965. Methods for estimating microtine abundance. Trans. North Amer. Wildl. Natur. Res. Conf. 30:393-400.

Hewson, R. 1976. Grazing by mountain hares Lepus timidus L., red deer Cervus elaphus $\mathrm{L}$. and red grouse Lagopus lagopus scoticus $\mathrm{L}$. on heather moorland in north east Scotland. J. Appl. Ecol. 13:657-666.

Jones, L.D.I. 1967. Studies on hill land in Wales. Tech Bull. No. 2 , Welsh Plant Breeding Station, Aberystwyth.

Kershaw, A.K. and J.H.H. Looney. 1985. Quantitative and dynamic plant ecology. Edward Amold, London.

Kotler, B.P., M.S. Gaines, and B.J. Danielson. 1988. The effects of vegetative cover on the community structure of prairie rodents. Acta Theriologica 33:379-391.

Lidicker, W.Z. 1973. Regulation of numbers in an island population of the California vole, a problem in community dynamics. Ecol. Monogr. 43:271-302.

Marrs, R.H., M. Bravington, and M. Rawes. 1988. Long-term vegetation changes in the Juncus squarrossus grassland at Moor House, northern England. Vegetatio 76:179-187.

Miles, J. 1988. Vegetation and soil changes in the uplands, p. 57-70. In: M.B. Usher and D.B.A. Thompson (eds), Ecological Change in the Uplands. Blackwell Scientific Publications, Oxford.

Miles, J., D. Welch, and S.B. Chapman. 1978. Vegetation and management in the uplands, p. 77-95. In: O.W. Heal (ed), Upland Land Use in England and Wales. Countryside Commission, Cheltenham.

Miller, G.R., A. Watson, and D. Jenkins. 1970. Responses of red grouse populations to experimental improvement of their food, $p$. 323-325. In: A. Watson (ed), Animal Populations in Relation to Their Food Resources. Blackwell Scientific Pub., Oxford.

Mitchell, B., D. McCowan, and D. Campbell. 1983. Faecal depositions as indicators of site use by red deer, p. 85-87. In: 1982 Annual Rep. Inst. of Terrestrial Ecol.

Nolan, A.J. and J.S. Robertson. 1987. Regional trends in dry and moist Scottish moorland vegetation in relation to climate, soils and other ecological factors. J. Ecol. 75:1145-1157.

Phillips, J.D.P. 1989. "Fingerprinting" of heather moorland. A rapid survey method for estates. Fifth Annual Report, The Joseph Nickerson, Reconciliation Project.

Ratcliffe, D.A. 1959. The vegetation of the Carneddau, North Wales I. Grasslands, heaths and bogs. J. Ecol. 47:371-413.

Rawes, M. 1981. Further results of excluding sheep from high-level grasslands in the north Pennines. J. Ecol. 69:651-669.

Rodwell, J.S. 1991. British Plant Communities, Cambridge Univ. Press, Cambridge.

SAS. 1982. S.A.S. User's Guide: Statistics, S.A.S. Institute, Cary, North Carolina.

Savory, C.J. 1986. Utilisation of different ages of heather on three Scottish moors by red grouse, mountain haries, sheep and red deer. Holarctic Ecol. 9:65-71.
Snedecor, G.W. and W.G. Cochran. 1967. Statistical Methods, 6th edition, The Iowa State Univ. Press, Ames, Iowa.

Smith, A.J.E. 1978. The Moss Flora of Britain and Ireland. Cambridge Univ. Press, Cambridge.

Sydes, C. and G.R. Miller. 1988. Range management and nature conservation in the British uplands, p. 323-328. In: M.B. Usher and D.B.A. Thompson, Ecological Change in the Uplands. Blackwell Scientific Publications, Oxford.

Taitt, M.J. and C.J. Krebs. 1983. Predation, cover and food manipulations during a spring decline of Microtus townsendii. J. Anim. Ecol. 52:837-848.

Taitt, M.J., J.H.W. Gipps, C.J. Krebs, and Z. Dunjerski. 1981. The effect of extra food and cover on declining populations of Microtus townsendii. Can. J. Zool. 59:1593-1599.

Tansley, A.G. 1939. The British Islands and their Vegetation, Cambridge Univ. Press, Cambridge

Tapper, S.C. 1979. The effect of fluctuating vole numbers (Microtus agrestis) on a population of weasels (Mustela nivalis) on farmland. $\mathrm{J}$ Anim. Ecol. 48:603-617.

Village, A. and D. Myhill. 1990. Estimating small mammal abundance for predator studies: snapstrapping versus sign indices. J. Zool. London, 222:681-689.

Watson, A., R. Moss, and R. Parr. 1987. Grouse increase on Mull. Landowning in Scotland, 207:6.

Welch, D. 1984a. Studies in the grazing of heather moorland in NorthEast Scotland III. Floristics. J. Appl. Ecol. 21:209-225.

Welch, D. 1984b. Studies in the grazing of heather moorland in NorthEast Scotland II. Responses of heather. J. Appl. Ecol. 21:197-207.

Welch, D., B.W. Staines, D.C. Catt, and D. Scott. 1990. Habitat useage by red (Cervus elaphus) and roe (Capreolus careolus) deer in a Scottish Sitka spruce plantation. J. Zool. London, 221:453-476.

Wiens, J.A. 1989. The Ecology of Bird Communities, Vol. 2: Processes and Variations. Cambridge Univ. Press, Cambridge.

\section{Associate Editor Nominations Journal of Range Management}

Replacements are needed for Associate Editors of the Journal of Range Management retiring from the Editorial Board in February 1997. We are seeking nominees with expertise in the following general areas: animal ecology, animal physiology, plant animal interactions, grazing management, plant physiology, plant ecology, improvements, reclamation, and measurement/sampling.

Associate Editors serve for 2 years with an optional 2 additional years with the concurrence of the Editor, JRM. To nominate a candidate for this important and demanding position, ascertain that the individual is available and willing to serve and then send a letter of nomination to the Editor describing the nominee's qualifications. Interested individuals may nominate themselves. The candidate will be asked to supply a list of publications and an account of experience in reviewing manuscripts.

Send nominations by 1 Aug. 1936 to: Gary Frasier, Editor, Journal of Range Management, 7820 Stag Hollow Road, Loveland, Colorado 80537. 